\title{
Primum non nocere: shared informed decision making in low back pain - a pilot cluster randomised trial
}

Shilpa Patel ${ }^{1 *}$, Anne Ngunjiri', Siew Wan Hee ${ }^{1}$, Yaling Yang ${ }^{2}$, Sally Brown ${ }^{3}$, Tim Friede ${ }^{4}$, Frances Griffiths ${ }^{1}$, Joanne Lord ${ }^{5}$, Harbinder Sandhu', Jill Thistlethwaite ${ }^{6}$, Colin Tysall ${ }^{3}$ and Martin Underwood ${ }^{1}$

\begin{abstract}
Background: Low back pain is a common and disabling condition leading to large health service and societal costs. Although there are several treatment options for back pain little is known about how to improve patient choice in treatment selection. The purpose of this study was to pilot a decision support package to help people choose between low back pain treatments.
\end{abstract}

Methods: This was a single-centred pilot cluster randomised controlled trial conducted in a community physiotherapy service. We included adults with non-specific low back pain referred for physiotherapy. Intervention participants were sent an information booklet prior to their first consultation. Intervention physiotherapists were trained to enhance their skills in shared informed decision making. Those in the control arm received care as usual. The primary outcome was satisfaction with the treatment received at four months using a five-point Likert Scale dichotomised into "satisfaction" (very satisfied or somewhat satisfied) and "non-satisfaction" (neither satisfied nor dissatisfied, somewhat dissatisfied or very dissatisfied).

Results: We recruited 148 participants. In the control arm $67 \%$ of participants were satisfied with their treatment and in the intervention arm 53\%. The adjusted relative risk of being satisfied was 1.28 (95\% confidence interval 0.79 to 2.09 ). For most secondary outcomes the trend was towards worse outcomes in the intervention group. For one measure; the Roland Morris Disability Questionnaire, this difference was clinically important (2.27, 95\% confidence interval 0.08 to 4.47). Mean healthcare costs were slightly lower ( $£ 38$ saving per patient) within the intervention arm but health outcomes were also less favourable (0.02 fewer QALYs); the estimated probability that the intervention would be cost-effective at an incremental threshold of $£ 20,000$ per QALY was $16 \%$.

Conclusion: We did not find that this decision support package improved satisfaction with treatment; it may have had a substantial negative effect on clinical outcome, and is very unlikely to prove cost-effective. That a decision support package might have a clinically important detrimental effect is of concern. To our knowledge this has not been observed previously. Decision support packages should be formally tested for clinical and cost-effectiveness, and safety before implementation.

Trial registration: Current Controlled Trials ISRCTN46035546 registered on 11/02/10.

Keywords: Back pain, Randomised control trial, Decision making

\footnotetext{
* Correspondence: shilpa.patel@warwick.ac.uk

${ }^{1}$ Division of Health Sciences, Warwick Medical School, University of Warwick, CV4 7AL Coventry, UK

Full list of author information is available at the end of the article
} 


\section{Background}

A patient centred model of health care is an explicit ambition of a number of established health care providers internationally including the UK National Health Service (NHS) [1]. The NHS is making a substantial investment in promoting shared decision making across a wide range of disorders through the 'Right Care' programme [2]. Shared informed decision making is one important part of the patient-centred model of care. To encourage and implement informed shared decision making, decision aids for patients have been developed to support treatment choice in many areas including breast cancer $[3,4]$, hypertension [5] and hormonal replacement therapy [6]. These patient decision aids provide information, evidence and guidance to help patients make decisions where there is some choice and where the decision may be influenced by the patient's values. Randomised controlled trials investigating the effectiveness of patient decision aids have shown positive effects on patient satisfaction with the decision-making process, enhanced knowledge acquisition and less decisional conflict or anxiety when making their decision on treatment preference [7-10]. In contrast, few trials have tested the effect of patient decision aids on clinical outcomes and overall these findings are not conclusive [11,12]. The few trials that report cost outcomes provide insufficient evidence to conclude that these interventions are cost saving; none report a cost-effectiveness analysis [13].

Low back pain is a common condition, which is associated with major occupational and healthcare costs [14-17] often leading to many years lost to disability [18]. In 2009, the National Institute for Health and Care Excellence (NICE) published guidance on the management of low back pain for those suffering with the condition from six weeks to one year. These guidelines recommend that people with persistent low back pain should be offered a choice of three core treatments: manual therapy, acupuncture, or supervised group exercise [19]. The guidelines also emphasise the need for clinicians to take into account the individual's needs and preferences as part of patient-centred care $[1,16]$.

Patients want more information about the available treatment options for their back pain to enable them to make better informed decisions [20-28]. Clinicians should therefore adopt a collaborative and shared approach to decision-making. This suggests a need for greater involvement by the patient in choosing the treatment they would most prefer, after a discussion with their health professional during which they have received factual information about different available options $[29,30]$. The practical application and evaluation of informed shared decision making in the non-surgical treatment of low back pain has, however, been limited.

In this pilot cluster randomised controlled trial (RCT) we tested the hypothesis that the use of a decision aid together with an informed shared decision-making consultation approach would improve satisfaction with treatment for patients referred to a community physiotherapy service for treatment of low back pain. A positive signal within this pilot study would justify proceeding to a full trial to test its clinical and cost-effectiveness.

\section{Methods}

\section{Trial design}

The study protocol and the intervention are described in detail elsewhere $[31,32]$. They are briefly summarised here. In our original study design we planned to randomise participants individually to treatment arms. Changes in the organisation of the appointment service around the time recruitment started meant we were unable to do this. We therefore, with agreement from the funder, changed to a cluster randomised design. Ethical approval was granted by Warwickshire REC $(10 / \mathrm{H} 1211 / 2)$.

\section{Participants}

We recruited participants aged 18 or over who had been referred to a single community physiotherapy department in Coventry for treatment of non-specific low back pain. All participants needed to be fluent in English. We excluded participants with severe psychiatric or personality disorders, a terminal or critical illness and those with possible serious spinal pathology (e.g. tumour, sepsis or fracture).

\section{Interventions}

Our intervention package was developed after exploratory work including literature reviews, a Delphi study, a nominal group with physiotherapists, focus groups with patients' and secondary analysis of existing interview data. We have described this process in detail elsewhere [32]. We developed a patient decision support package in the form of a booklet and associated training for the physiotherapists [32] (Additional file 1). The physiotherapist training was a two-hour session to enable the therapists to develop an understanding of how to incorporate the decision support package within their patient-centred consultations, facilitate patient involvement as well as providing appropriate information by recognising and responding to patient concerns.

The intervention consisted of a patient booklet that details the available treatment options which include exercise, manual therapy, acupuncture, and a cognitive behavioural approach. The booklet also provided answers to the frequently asked questions associated with each option. Space was provided in the booklet to enable patients to note if they felt they had sufficient information and any points they wanted to discuss in the consultation. This was posted ahead of the participant's first 
consultation and used as a basis for discussion when they attended.

Those allocated to a therapist in the usual care arm attended their appointment without any prior treatment information and with a therapist not trained on informed shared decision making.

\section{Procedure}

Once a general practitioner referral was received, patients were given an appointment by a booking clerk who was blind to the physiotherapists' allocation. These patients were then sent an invitation to join the study. Each invitation pack contained an invitation letter, patient information sheet, consent form, baseline questionnaire and reply slip. The invitation advised participants that the trial was looking at whether giving physiotherapists additional training will improve their satisfaction with their choice of back pain treatments. Participants were advised that they would be randomly assigned to either a specially trained physiotherapist or a physiotherapist who had not had the additional training. Potential participants returned the consent form and completed baseline questionnaire to the research team at Warwick Clinical Trials Unit. Those who met the inclusion criteria, completed the baseline questionnaire and consented to the trial were included.

Once the baseline questionnaire was received those participants allocated to a therapist in the intervention arm of the study were sent a copy of the decision support booklet by post from the physiotherapy department; typically around two weeks prior to their first consultation [32]. Participants were then expected to attend their appointment as usual. Those allocated to a therapist in the usual care arm attended their appointment as usual.

\section{Outcomes}

The primary outcome measure was satisfaction with treatment at four months using a five-point Likert Scale (very satisfied to very dissatisfied) dichotomised into "satisfaction" (very satisfied or somewhat satisfied) and "non-satisfaction" (neither satisfied nor dissatisfied, somewhat dissatisfied or very dissatisfied).

Participants were sent a satisfaction with decision scale [33] to complete soon after the planned initial consultation. Other secondary outcome measures collected at four months were the Roland Morris Disability Questionnaire [34], modified Von Korff pain and disability scales [35], SF-12 [36], EQ-5D [37], hospital anxiety and depression scale [38], pain self-efficacy questionnaire [39], and the fear avoidance beliefs questionnaire [40].

Outcome measures were collected at baseline and four months after entering the trial by which time we would expect all treatment to have been completed and any positive effects maximised. In addition we sent an immediate follow-up questionnaire looking at satisfaction with decision soon after the date of their first appointment. We sent two postal reminders; if necessary this was followed by a phone call from the study team member, who was blind to treatment allocation, to collect the primary outcome and modified Von Korff scales [35].

\section{Sample size}

To show an improvement of $25 \%$ in satisfaction with treatment from $50 \%$ in the control arm at the 5\% significance level with $80 \%$ power requires data on 116 subjects. Although such satisfaction measures are prone to ceiling effect we have used a dichotomised scale. Allowing for $20 \%$ loss to follow-up we originally aimed to recruit 150 subjects. With the change in design (from individual randomised to cluster randomised trial) we needed to account for clustering effects. We did a blinded interim sample size review [41] after we had recruited 41 participants to estimate the intra-cluster correlation coefficient (ICC) to allow a re-calculation of sample size. The estimated ICC was close to zero and there were 14 clusters with size ranges from one to six. Thus, the revised sample size was based on 14 clusters with an average cluster size of nine and assuming, conservatively, an ICC of 0.01 , a $5 \%$ significance level and $80 \%$ power, and allowing a $20 \%$ of loss to follow-up, the total sample size needed was 158 .

\section{Randomisation}

Using stratified block randomisation all physiotherapists working in the service were randomised to deliver either the usual care or the decision support package intervention in a 1:1 ratio, stratified by their number of years of experience ( $\leq 6$ vs. $>6$ years since their qualification) and the amount of time they worked for the service each week. The randomisation was set up by an independent statistician. Members of the team were blind to the allocation of participants to physiotherapists. Practical constraints meant that we were unable to train and randomise any new physiotherapists joining the service after the trial had started. Participants consulting the newly started physiotherapists were all assigned to control.

\section{Statistical methods}

The statistical team (SWH, TF) developed a statistical analysis plan that was agreed by the study team prior to a database freeze and unblinding of the data. The main summary and analysis were intention to treat. Continuous variables at baseline and follow-ups were summarised as mean, standard deviation, median and interquartile range. Categorical variables were summarised as frequency and percentage. The primary outcome, satisfaction with treatment, was dichotomised into "satisfaction" and "non- 
satisfaction." Secondary outcomes were summarised as change from baseline. The ICC and its confidence interval for the primary outcome was also summarised [42]. Dichotomous outcomes were modelled with generalised linear mixed effects regression with logit link and continuous outcomes were analysed using Gaussian linear mixed effects models. For ease of interpretation results were transformed from the odds ratio to the relative risk scale. The estimation was obtained in the same manner as for odds ratio but with log link. The study arm, physiotherapists' years of experience ( $\leq 6$ vs. $>6$ years) and the pain severity (modified Von Korff pain score measured at baseline) formed the fixed effects whilst the physiotherapists (clusters) formed the random effects. In a sensitivity analysis physiotherapists recruited post-randomisation were excluded. All statistical analyses were two-sided and point estimates were reported with the corresponding 95\% confidence interval.

Cost-effectiveness analysis was conducted in line with the NICE reference case [43] and International Society for Pharmacoeconomics and Outcome Research recommendations [44]. We estimated the total cost of back pain related NHS care over four months. Costs for the decision support package included printing and delivery of the package to patients, and training for physiotherapists. Participants' use of other NHS services for back pain was obtained from the follow-up questionnaire and physiotherapy records. Unit costs for health services were identified from standard national sources. The effectiveness of the decision support package and usual care were measured using quality adjusted life years (QALYs), estimated using the 'area under the curve' approach from EQ-5D data.

Missing resource use and utility data were imputed and integrated in the cost-effectiveness analysis using multiple imputation methods. The Stata Multivariate Imputation using Chained Equations (MICE) procedure was used to estimate missing resource use and EQ-5D observations based on patients' age, gender, baseline RMDQ score and treatment group. Between-group differences in mean costs and QALYs were estimated using bootstrap regression of the imputed datasets. The seemingly unrelated regression method [45] was used to simultaneously estimate differences of costs and QALYs between treatment arms, adjusting for patient age, sex, Roland Morris Disability Questionnaire and EQ-5D scores at baseline, and physiotherapist experience. A simple model was used to extrapolate between-group differences in QALYs and costs (excluding the cost of the decision support package itself) at the end of the trial to a maximum of one year from baseline. This was based on the results of a published meta-analysis of low back pain trial data [46]. Analyses were done in SAS 9.3 and Stata 11.0.

\section{Results}

A total of 19 physiotherapists were involved in the trial. Twelve physiotherapists were present at the start of the trial, and seven were randomised to the decision support arm. Of the seven physiotherapists in the intervention arm, four had more than six years of experience, whereas of the five who were randomised to the control arm only one of them had more than six years of experience (Table 1). The other seven physiotherapists who joined the department after randomisation were allocated to the control arm and four of them had more than six years of experience.

We approached 238 people to take part in the trial; 148 (62\%) joined the study. The baseline characteristics of the two groups were similar (Table 2). Eighty-five (57\%) participants were assigned to the decision support arm. We obtained four-month follow-up data on 119 $(80 \%)$ of our participants (Figure 1). Of these 114 had complete data for both primary endpoint and baseline data for analysis. The adjusted percentage satisfied with their treatment in the intervention arm was $53 \%(n=33 / 63)$ and in the control arm it was $67 \%(\mathrm{n}=34 / 51)$. The adjusted odds ratio was 1.85 (95\% confidence interval 0.65 to 5.25 : the estimated ICC was $0.018 ;-0.11$ to 0.15$)$. Correspondingly, the adjusted relative risk was 1.28 (0.79 to 2.09). We infer that the rate of satisfied with treatments in the control arm was between 0.79 and 2.09 times that for those in the intervention arm.

For all but one of our secondary outcomes the point estimate for the difference favours the control intervention. The exception is the SF-12 mental component scores (Table 3, Figure 2). For the Roland Morris Disability Questionnaire the difference between treatment arms was -2.27 ( -4.47 to -0.08$)$.

The responses to the satisfaction with decision questionnaire were dichotomised to "agreement" and "non-agreement." A total of 103 participants returned the immediate

\begin{tabular}{|c|c|c|c|c|}
\hline & & \multicolumn{3}{|c|}{ Treatment arms } \\
\hline \multicolumn{2}{|c|}{ Years of experience } & Intervention & Control & $\begin{array}{c}\text { Control } \\
\text { (post-randomization) }\end{array}$ \\
\hline \multirow[t]{4}{*}{$\begin{array}{l}<=6 \\
\text { years }\end{array}$} & $\begin{array}{l}\text { No. of } \\
\text { physiotherapists }\end{array}$ & 3 & 4 & 3 \\
\hline & No. of patients & 38 & 23 & 10 \\
\hline & Median & 12 & 6 & 1 \\
\hline & $(\min , \max )$ & $(12,14)$ & $(3,8)$ & $(1,8)$ \\
\hline \multirow[t]{4}{*}{$\begin{array}{l}>6 \\
\text { years }\end{array}$} & $\begin{array}{l}\text { No. of } \\
\text { physiotherapists }\end{array}$ & 4 & 1 & 4 \\
\hline & No. of patients & 30 & 10 & 8 \\
\hline & Median & 8.5 & 10 & 1 \\
\hline & (min, max) & $(2,11)$ & $(10,10)$ & $(1,5)$ \\
\hline
\end{tabular}


Table 2 Demographic and clinical characteristics of respondents at baseline

\begin{tabular}{|c|c|c|c|c|}
\hline & \multicolumn{2}{|c|}{ Decision support package } & \multicolumn{2}{|c|}{ Usual care } \\
\hline & $n$ & (\%) & $n$ & (\%) \\
\hline No. of participants & 85 & $(57.4)$ & 63 & $(42.6)$ \\
\hline \multicolumn{5}{|l|}{ Age, years } \\
\hline Mean (SD) & 46.9 & $(13.8)$ & 48.8 & $(16.7)$ \\
\hline Median (IQR) & 47.6 & $(36.1,56.9)$ & 46.8 & $(33.5,63.4$ \\
\hline \multicolumn{5}{|l|}{ Sex: } \\
\hline Male & 28 & $(32.9)$ & 22 & $(34.9)$ \\
\hline Female & 57 & $(67.1)$ & 41 & $(65.1)$ \\
\hline \multicolumn{5}{|l|}{ Ethnicity: } \\
\hline White & 71 & $(83.5)$ & 56 & $(88.9)$ \\
\hline Mixed & 3 & (3.5) & 2 & $(3.2)$ \\
\hline Asian or Asian British & 7 & $(8.2)$ & 3 & $(4.8)$ \\
\hline Black or Black British & 3 & $(3.5)$ & 2 & $(3.2)$ \\
\hline Chinese & 1 & $(1.2)$ & 0 & $(0.0)$ \\
\hline \multicolumn{5}{|l|}{ Currently working: } \\
\hline Yes & 45 & $(52.9)$ & 35 & $(55.6)$ \\
\hline No: & 40 & $(47.1)$ & 28 & $(44.4)$ \\
\hline Retired & 13 & $(31.7)$ & 14 & $(46.7)$ \\
\hline Stay at home & 4 & (9.8) & 3 & $(10.0)$ \\
\hline Unable to work due to low back pain & 8 & $(19.5)$ & 8 & $(26.7)$ \\
\hline Unable to work due to other illness & 6 & $(14.6)$ & 2 & $(6.7)$ \\
\hline Unemployed and looking for work & 3 & $(7.3)$ & 1 & (3.3) \\
\hline In full time education & 2 & $(4.9)$ & 0 & $(0.0)$ \\
\hline Others & 5 & $(12.2)$ & 2 & $(6.7)$ \\
\hline \multicolumn{5}{|l|}{ Hours of paid work per week: } \\
\hline No. of participants & 49 & & 38 & \\
\hline Mean (SD) & 31.8 & $(12.6)$ & 30.2 & $(12.4)$ \\
\hline Median (IQR) & 37 & $(25,40)$ & 35 & $(21,39)$ \\
\hline \multicolumn{5}{|l|}{ Pain in lower back pain in the last four weeks: } \\
\hline Yes & 85 & $(100.0)$ & 63 & $(100.0)$ \\
\hline \multicolumn{5}{|l|}{ If Yes: } \\
\hline \multicolumn{5}{|c|}{ Pain limit usual activities for more than one day: } \\
\hline Yes & 70 & $(84.3)$ & 54 & $(85.7)$ \\
\hline No & 13 & $(15.7)$ & 9 & $(14.3)$ \\
\hline \multicolumn{5}{|l|}{ Frequency of lower back pain: } \\
\hline On some days & 4 & $(4.7)$ & 4 & $(6.4)$ \\
\hline On most days & 13 & $(15.3)$ & 12 & $(19.1)$ \\
\hline Everyday & 68 & $(80.0)$ & 47 & $(74.6)$ \\
\hline \multicolumn{5}{|c|}{ The length of time since free of low back pain for one whole month: } \\
\hline$<3$ months ago & 23 & $(27.4)$ & 21 & (33.3) \\
\hline$\geq 3$ months ago but $<7$ months ago & 18 & $(21.4)$ & 5 & $(7.9)$ \\
\hline$\geq 7$ months ago but $<3$ years ago & 26 & $(31.0)$ & 24 & $(38.1)$ \\
\hline$\geq 3$ years ago & 17 & $(20.2)$ & 13 & $(20.6)$ \\
\hline
\end{tabular}

Pain down the leg: 
Table 2 Demographic and clinical characteristics of respondents at baseline (Continued)

\begin{tabular}{|c|c|c|c|c|}
\hline Yes & 62 & $(72.9)$ & 46 & $(73.0)$ \\
\hline No & 23 & $(27.1)$ & 17 & $(27.0)$ \\
\hline \multicolumn{5}{|l|}{ If Yes: } \\
\hline \multicolumn{5}{|c|}{ Pain spread below the knee: } \\
\hline Yes & 38 & $(62.3)$ & 27 & $(58.7)$ \\
\hline No & 23 & $(37.7)$ & 19 & $(41.3)$ \\
\hline \multicolumn{5}{|c|}{ Roland Morris disability questionnaire $(0-24,0=$ best $)$} \\
\hline No. of participants & 85 & & 63 & \\
\hline Mean (SD) & 10.66 & 5.9 & 10.6 & 5.3 \\
\hline Median (IQR) & 11.0 & $(6.0,14.0)$ & 11.0 & $(6.0,14.0)$ \\
\hline \multicolumn{5}{|c|}{ Modified Von Korff disability score ( $0-100,0=$ best $)$} \\
\hline No. of participants & 84 & & 62 & \\
\hline Mean (SD) & 61.3 & 23.9 & 56.8 & 26.0 \\
\hline Median (IQR) & 65.0 & $(48.3,80.0)$ & 58.3 & $(40.0,76.7)$ \\
\hline \multicolumn{5}{|c|}{ Modified Von Korff pain score $(0-100,0=$ best $)$} \\
\hline No. of participants & 84 & & 63 & \\
\hline Mean (SD) & 68.5 & 20.3 & 67.1 & 17.2 \\
\hline Median (IQR) & 73.3 & $(53.3,83.3)$ & 70.0 & $(56.7,80.0)$ \\
\hline \multicolumn{5}{|c|}{ Norm-based physical component score of SF-12 (0-100, $100=$ best) } \\
\hline No. of participants & 85 & & 55 & \\
\hline Mean (SD) & 34.6 & 9.5 & 35.1 & 9.0 \\
\hline Median (IQR) & 33.5 & $(27.2,42.8)$ & 34.3 & $(29.0,40.0)$ \\
\hline \multicolumn{5}{|c|}{ Norm-based mental component score of SF-12 (0-100, $100=$ best) } \\
\hline No. of participants & 85 & & 55 & \\
\hline Mean (SD) & 42.6 & 12.8 & 44.4 & 12.2 \\
\hline Median (IQR) & 42.7 & $(34.8,53.6)$ & 44.9 & $(37.2,54.2)$ \\
\hline \multicolumn{5}{|c|}{ Hospital anxiety and depression scale: anxiety $(0-21,0=$ best $)$} \\
\hline No. of participants & 83 & & 60 & \\
\hline Mean (SD) & 7.6 & 4.4 & 7.5 & 4.2 \\
\hline Median (IQR) & 7.0 & $(4.0,11.0)$ & 7 & $(4.5,11.5)$ \\
\hline \multicolumn{5}{|c|}{ Hospital anxiety and depression scale: depression ( $0-21,0=$ best $)$} \\
\hline No. of participants & 82 & & 59 & \\
\hline Mean (SD) & 7.2 & 4.7 & 7.2 & 5.0 \\
\hline Median (IQR) & 6.5 & $(4.0,10.0)$ & 7 & $(3.0,11.0)$ \\
\hline \multicolumn{5}{|c|}{ Pain self-efficacy questionnaire $(0-60,60=$ best $)$} \\
\hline No. of participants & 82 & & 61 & \\
\hline Mean (SD) & 34.2 & 15.6 & 31.5 & 14.8 \\
\hline Median (IQR) & 37.0 & $(24.0,44.0)$ & 32.0 & $(19.0,45.0)$ \\
\hline \multicolumn{5}{|c|}{ Fear avoidance beliefs questionnaire ( $0-24,0=$ best $)$} \\
\hline No. of participants & 85 & & 59 & \\
\hline Mean (SD) & 14.3 & 5.9 & 15.5 & 5.5 \\
\hline Median (IQR) & 15 & $(10.0,18.0)$ & 17 & $(12.0,19.0)$ \\
\hline
\end{tabular}

Abbreviations: $S D$ standard deviation; IQR interquartile range. 


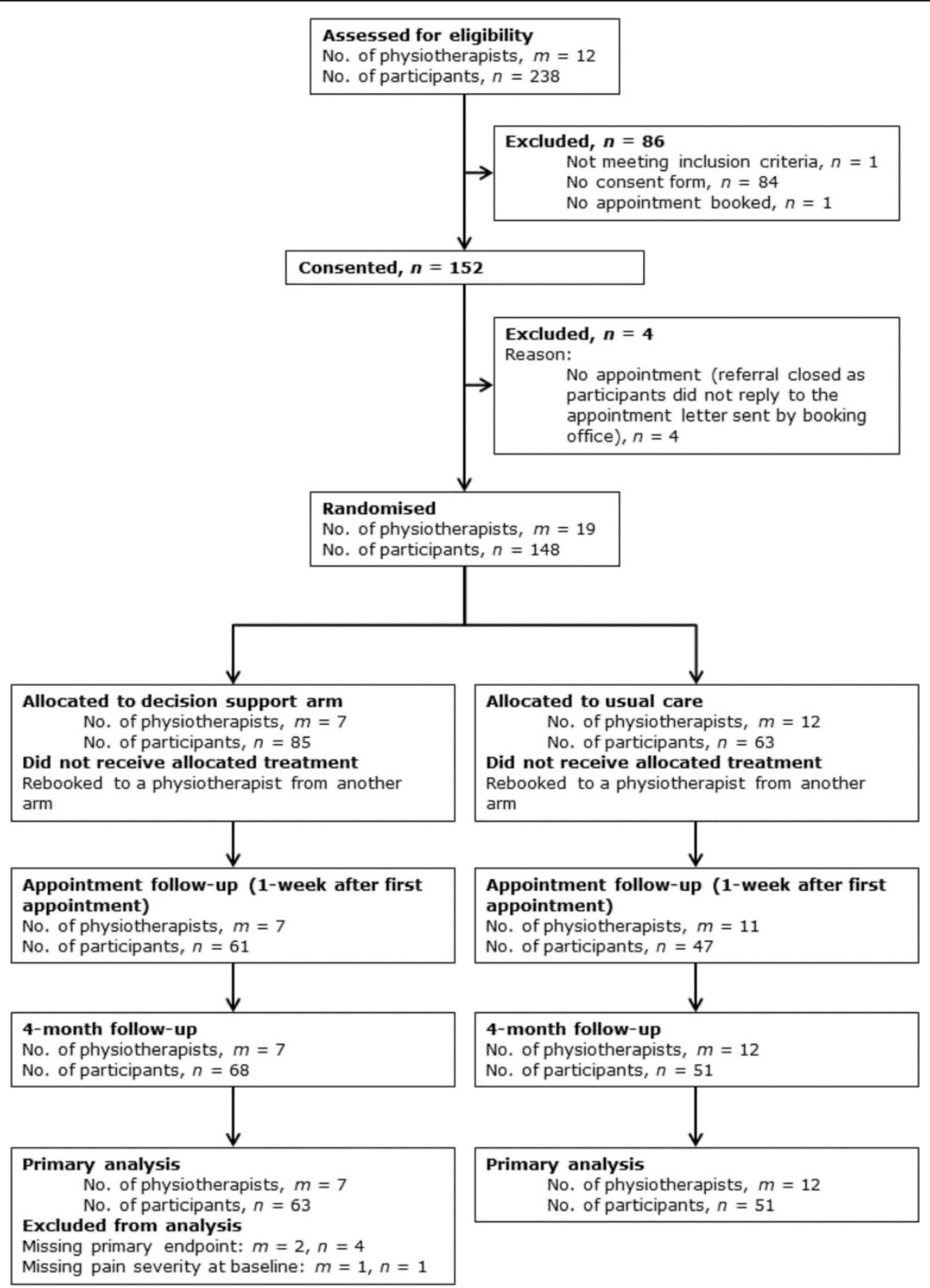

Figure 1 CONSORT chart.

follow-up questionnaire. Participants from both arms were similarly satisfied with their decision (Table 4).

The estimated cost of the decision support intervention was $£ 19.44$ per person (comprising $£ 2.20$ for consumables and $£ 17.24$ for physiotherapist training). Participants' use of NHS services for back pain and unit costs for those health services were presented in Table 5 and Additional file 2: Table S1. Mean estimated costs for other NHS services related to back pain over the trial period in the intervention $(n=45)$ and control $(n=35)$ arms were $£ 245$ and $£ 271$, respectively (mean difference
$£ 25.76,-116.54$ to 168.05$)$ (Additional file 3: Table S2). Mean QALYs gained on the basis of EQ-5D data (Table 6) over the four-month trial period were lower for the decision support arm $(n=57)$ than usual care $(\mathrm{n}=38)$ arm: 0.18 and 0.22 , respectively (mean difference $0.03,-0.01$ to 0.07$)$.

The regression-based estimates using imputed data and adjusting for baseline differences between the groups gave similar results: over four months, mean estimated costs were $£ 38$ cheaper but mean estimated QALYs were also 0.02 lower in the decision support arm 
Table 3 Secondary outcome measures; number of participants contributed to the analysis (first row), mean change from baseline and difference between treatments with $95 \%$ confidence interval

\begin{tabular}{|c|c|c|}
\hline \multicolumn{2}{|c|}{ Mean change from baseline } & \multirow{2}{*}{$\begin{array}{l}\text { Mean treatment } \\
\text { difference* }\end{array}$} \\
\hline Decision support package & Usual care & \\
\hline \multicolumn{3}{|c|}{ Roland Morris disability questionnaire (positive change = improvement) } \\
\hline$n=58$ & $n=40$ & \\
\hline $1.9(0.5$ to 3.3$)$ & $4.2(2.5$ to 5.9$)$ & $-2.27(-4.47$ to -0.08$)$ \\
\hline \multicolumn{3}{|c|}{ Modified Von Korff disability score (positive change = improvement) } \\
\hline$n=64$ & $n=49$ & \\
\hline 17.1 (10.9 to 23.3$)$ & $18.2(11.0$ to 25.3$)$ & $-1.07(-10.50$ to 8.37$)$ \\
\hline \multicolumn{3}{|c|}{ Modified Von Korff pain score (positive change = improvement) } \\
\hline$n=66$ & $n=50$ & \\
\hline 14.7 (7.6 to 21.9$)$ & $24.0(16.6$ to 31.4$)$ & $-9.24(-19.44$ to 0.96$)$ \\
\hline
\end{tabular}

Norm-based physical component score of SF-12 (negative change $=$ improvement)

$$
n=53 \quad n=35
$$$$
-5.5(-7.7 \text { to }-3.3) \quad-6.3(-9.1 \text { to }-3.6) \quad 0.80(-2.71 \text { to } 4.32)
$$

Norm-based mental component score of SF-12 (negative change $=$ improvement)

$$
\begin{array}{ccc}
n=53 & n=35 \\
-3.4(-6.4 \text { to }-0.4) & -1.8(-5.5 \text { to } 1.9) & -1.64(-6.36 \text { to } 3.09)
\end{array}
$$

Hospital anxiety and depression scale: anxiety (positive change $=$ improvement)

$$
\begin{array}{ccc}
n=57 & n=36 \\
0.5(-0.5 \text { to } 1.5) & 1.0(-0.2 \text { to } 2.2) & -0.46(-2.01 \text { to } 1.09)
\end{array}
$$

Hospital anxiety and depression scale: depression (positive change $=$ improvement)

$$
\begin{array}{ccc}
n=55 & n=36 \\
1.1(0.2 \text { to } 2.0) & 2.2(1.1 \text { to } 3.3) & -1.12(-2.52 \text { to } 0.28)
\end{array}
$$

Pain self-efficacy questionnaire (negative change $=$ improvement)

$$
\begin{array}{ccc}
n=57 & n=38 \\
-4.6(-9.4 \text { to } 0.2) & -7.3(-12.2 \text { to }-2.5) & 2.74(-4.04 \text { to } 9.51)
\end{array}
$$

Fear avoidance beliefs questionnaire (positive change $=$ improvement)

$$
\begin{array}{ccc}
n=56 & n=36 \\
2.0(0.2 \text { to } 3.9) & 2.1(-0.2 \text { to } 4.4) & -0.09(-3.04 \text { to } 2.87)
\end{array}
$$

${ }^{*}$ Mean difference $=$ (decision support package - usual care) after adjusting for years of experience and pain severity at baseline as fixed effects and physiotherapist as random effects; negative difference = favours usual care.

than with usual care. These estimates give an incremental cost effectiveness ratio of $£ 1900$ ( $£ 38 / 0.02)$ per QALY gained for usual care compared with the decision support package, suggesting that the decision support intervention would not be cost-effective. The extent of uncertainty over the cost-effectiveness results is illustrated by the cost-effectiveness plane and the cost effectiveness acceptability curve (Figure 3 and Additional file 4: Figure S1). They show that the decision support package is unlikely to be cost-effective: with only $16 \%$ probability of being cost-effective at a threshold of $£ 20,000$ per QALY gained. The expected value of perfect information estimated from our base case is $£ 30$ per patient and $£ 67$ per patient when costs and QALYs are extrapolated up to one year from baseline.

\section{Discussion}

Despite having a carefully designed decision support package we have failed to show an improvement in satisfaction with treatment. The striking finding here is that for our primary outcome and for all but one of our secondary outcomes the direction of change is neutral or favours the control arm. For one of these; the Roland Morris Disability Questionnaire this difference appears clinically important. The Roland Morris Disability Questionnaire is the leading primary outcome in community based back pain studies [47]. The point estimate of the dis-benefit from the decision support package at 2.3 points ( $95 \%$ CI 0.1 to 4.5 ) is larger than the effect size found in the definitive trials supporting the use of the back pain treatments included in the decision support package. Previous back pain trials have reported a net benefit on the Roland Morris Disability Questionnaire at three months of 1.4 (95\% CI 0.6 to 2.1) for an exercise programme, 1.6 (95\% CI 0.8 to 2.3 ) for a manipulation package and 1.1 points, $(0.37$ to 1.74$)$ for a group cognitive behavioural approach $[48,49]$. This means that the beneficial effects of physiotherapy treatment might be negated by our decision support package.

One of the main strengths of this trial is the rigorous design of the intervention package; that has itself been subject to external peer review [32]. The intervention was developed systematically using the International Patient Decision Aid Standards Collaboration (IPDAS) framework and its related checklist [50,51]. These cover best practice in the development of decision support packages. The training package for the physiotherapist was grounded in principles from the Calgary-Cambridge Guidelines [52]. The training was designed and delivered by a Health Psychologist (HS) with expertise in communication skills.

Some caution is needed in interpreting these data because this is a pilot study run in one community physiotherapy service thus the results may not be generalisable. Nevertheless, the study was still adequately powered to test the effect of our intervention on treatment satisfaction. It is one of a very small number of trials of decision aids that have collected patient reported outcomes and the only trial, of which we are aware, to have reported a cost-effectiveness analysis [13]. Some caution is needed in interpreting the economic data because of the large amount of missing data. Nevertheless, we have demonstrated that our intervention does not improve satisfaction, it may produce worse clinical outcomes, and that it is unlikely to be a cost-effective option. 


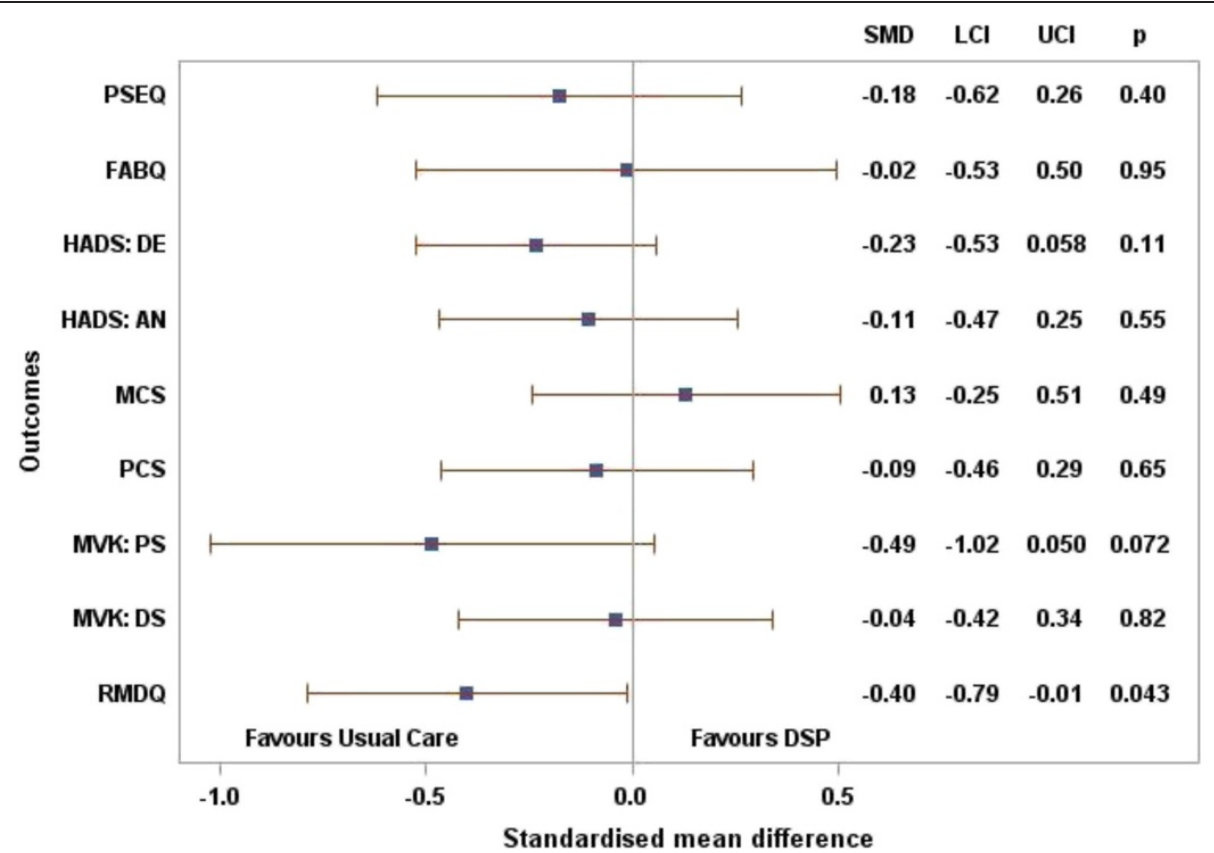

Figure 2 Secondary outcomes; standardised mean difference with $95 \%$ confidence interval after adjusting for physiotherapist's years of experience and pain severity at baseline as fixed effects and physiotherapist as random effects.

That we were not able to randomise those therapists joining the department after the initial training compromises our randomisation potentially leading to bias. That the allocation of patients to physiotherapists was managed by the department's appointment staff blind to randomisation gives some reassurance that the two groups should have been well matched for unmeasured confounders at baseline. Since new appointees tended to

Table 4 Summary of satisfaction with decision

\begin{tabular}{|c|c|c|c|}
\hline Decision & oackage & & \\
\hline$n / N$ & (\%) & $n / N$ & (\%) \\
\hline
\end{tabular}

Satisfied that I was adequately informed about the issues important to treatment decision

$$
\begin{array}{lll}
\text { Agreement* } & \text { 478) } \quad \text { (78) }
\end{array}
$$

The decision I made was the best decision possible for me personally

$$
\text { Agreement* } \quad 46 / 58 \quad \text { (79) } \quad 35 / 45 \quad \text { (78) }
$$

Satisfied that my decision was consistent with my personal values

$$
\text { Agreement* } \quad 47 / 57 \quad \text { (83) } \quad 36 / 44
$$

Expect to successfully carry out (or continue to carry out) the decision I made

$$
\text { Agreement* } \quad 48 / 58 \quad \text { (83) } \quad 37 / 43
$$

Satisfied that this was my decision to make

$$
\text { Agreement* }^{*} \quad 46 / 58 \quad \text { (79) } \quad 34 / 43
$$

Satisfied with my decision

$\begin{array}{llll}\text { Agreement* } & 47 / 58 & \text { (81) } & 35 / 43\end{array}$

be more inexperienced we judged that the direction of any bias would be towards reducing any positive effect size. In light of our results we did an additional post-hoc sensitivity analysis, for the RMDQ, excluding participants treated by physiotherapists recruited after randomisation. This showed the between group difference in the RMDQ of 3.11 (95\% CI 0.51 - 5.71). This does not suggest that any bias introduced would substantially affect our conclusions (Additional file 5: Table S3).

The 2011 Cochrane review of decision aids did not identify any apparent adverse effects on health outcomes or satisfaction in 86 trials of decision support [11]. The authors did note the risk of bias from possible failure to report negative outcomes in published studies. Our data are not sufficient to conclude unequivocally that this decision support package is harmful. The harm identified might reflect no more than random chance in a study with multiple outcomes. Nevertheless, the overall trend across our pool of outcomes is to favour the control intervention and the harm identified was in a measure which would have been likely to be chosen as a primary outcome in any definitive trial. It would be difficult to justify a further randomised trial to confirm our findings.

We hypothesise that this decision support package introduced uncertainty about the overall effectiveness of the available treatment options, both in terms of their modest effect sizes and the weakness of the underpinning evidence, thus reducing expectation of benefit. Our promotion of evidence based practice and shared decision making may have affected the therapist-patient 
Table 5 Mean NHS service use: 0-4 months

\begin{tabular}{|c|c|c|c|c|c|}
\hline & \multicolumn{2}{|c|}{ Number of patients } & \multicolumn{2}{|c|}{ Mean quantity } & \multirow{2}{*}{$\begin{array}{l}\text { Mean treatment difference } \\
(95 \% \mathrm{Cl}) \text { (usual care - DSP) }\end{array}$} \\
\hline & $\overline{\mathrm{DSP}}$ & Usual care & DSP (SD) & Usual care (SD) & \\
\hline \multicolumn{6}{|l|}{ NHS Services } \\
\hline General Practitioner & 57 & 39 & $1.4(2.1)$ & $1.1(1.5)$ & $-0.28(-1.05$ to 0.50$)$ \\
\hline Practice nurse & 58 & 39 & $0.1(0.4)$ & $0.03(0.2)$ & $-0.08(-0.21$ to 0.06$)$ \\
\hline Physiotherapist visit** & 81 & 60 & $3.8(3.7)$ & $3.1(3.7)$ & $0.72(-1.97$ to 0.52$)$ \\
\hline Doctor/nurse in an emergency department(casualty) & 58 & 39 & $0.2(0.7)$ & $0.1(0.3)$ & $-0.10(-0.34$ to 0.13$)$ \\
\hline Hospital specialist (consultant or team member) & 58 & 39 & $0.1(0.5)$ & $0.5(1.5)$ & $0.42(-0.00$ to 0.84$)$ \\
\hline Psychologist/counsellor & 58 & 39 & $0.03(2.3)$ & $0.1(0.5)$ & $0.04(-0.11$ to 0.19$)$ \\
\hline Hospital stay & 57 & 40 & $0.04(0.2)$ & $0(0)$ & $-0.04(-0.09$ to 0.02$)$ \\
\hline \multicolumn{6}{|l|}{ NHS Tests } \\
\hline X-rays & 58 & 39 & $0.1(0.3)$ & $0.0(0.2)$ & $0.03(-0.14$ to 0.07$)$ \\
\hline CT scan & 58 & 39 & $0.02(0.1)$ & $0.03(0.2)$ & $0.01(-0.05$ to 0.07$)$ \\
\hline MRI scan & 57 & 39 & $0.1(0.3)$ & $0.3(0.6)$ & $0.16(-0.04$ to 0.36$)$ \\
\hline Blood tests & 58 & 39 & $0.2(0.5)$ & $0.1(0.3)$ & $0.05(-0.22$ to 0.11$)$ \\
\hline \multicolumn{6}{|l|}{ NHS Drugs } \\
\hline Pain killers & 57 & 39 & $1.2(2.0)$ & $1.3(1.5)$ & $0.08(-0.67$ to 0.83$)$ \\
\hline Anti-inflammatory drugs & 58 & 39 & $0.8(1.3)$ & $0.9(1.2)$ & $0.08(-0.43$ to 0.58$)$ \\
\hline Gels/creams & 58 & 39 & $0.2(0.5)$ & $0.1(0.2)$ & $0.11(-0.28$ to 0.07$)$ \\
\hline Sleeping pills & 58 & 39 & $0.1(0.5)$ & $0.1(0.4)$ & $0.04(-0.24$ to 0.16$)$ \\
\hline Anti-depressants & 58 & 39 & $0.2(0.7)$ & $0.4(0.9)$ & $0.17(-0.16$ to 0.50$)$ \\
\hline
\end{tabular}

**Based on physiotherapist's medical record.

Table 6 Utility weights and quality-adjusted life years estimates

\begin{tabular}{|c|c|c|c|c|c|}
\hline & \multicolumn{2}{|c|}{ Number of patients } & \multicolumn{2}{|c|}{ Mean (SD) } & \multirow{2}{*}{$\begin{array}{l}\text { Mean treatment } \\
\text { difference } \\
(95 \% \mathrm{Cl})(\text { Usual } \\
\text { care - DSP) }\end{array}$} \\
\hline & DSP & Usual care & DSP & Usual care & \\
\hline \multicolumn{6}{|l|}{ EQ-5D: } \\
\hline Baseline & 84 & 61 & $0.4(0.4)$ & $0.5(0.3)$ & $0.01(-0.10$ to 0.12$)$ \\
\hline 4 month & 58 & 39 & $0.5(0.4)$ & $0.7(0.3)$ & $0.13(-0.01$ to 0.26$)$ \\
\hline Change from baseline to 4-month & 57 & 38 & $0.1(0.3)$ & $0.2(0.3)$ & $0.05(-0.05$ to 0.16$)$ \\
\hline QALY gains (AUC 0-4 month) & 57 & 38 & $0.2(0.1)$ & $0.2(0.1)$ & $0.03(-0.01$ to 0.07$)$ \\
\hline \multicolumn{6}{|l|}{ SF-6D: } \\
\hline Baseline & 85 & 59 & $0.6(0.1)$ & $0.6(0.2)$ & $0.02(-0.03$ to 0.06$)$ \\
\hline 4 months & 57 & 39 & $0.7(0.2)$ & $0.7(0.2)$ & $0.03(-0.03$ to 0.10$)$ \\
\hline Change from baseline to 4-month & 57 & 37 & $0.1(0.1)$ & $0.1(0.2)$ & $0.03(-0.03$ to 0.08$)$ \\
\hline QALY gains (AUC baseline to 4-month) & 57 & 37 & $0.2(0.1)$ & $0.2(0.1)$ & $0.01(-0.01$ to 0.03$)$ \\
\hline \multicolumn{6}{|l|}{ EQ-VAS: } \\
\hline Baseline & 83 & 60 & $54.7(26.3)$ & $59.0(20.6)$ & $4.35(-3.72$ to 12.42$)$ \\
\hline 4 months & 55 & 37 & $68.0(22.6)$ & $67.7(18.3)$ & $-0.28(-9.14$ to 8.59$)$ \\
\hline Change from baseline to 4-month & 54 & 36 & $9.0(21.0)$ & $8.1(15.9)$ & $-0.98(-9.16$ to 7.20$)$ \\
\hline
\end{tabular}

Abbreviations: DSP decision support package; SD standard deviation; $C I$ confidence interval; QALY quality-adjusted life years; $A U C$ area under the curve. 


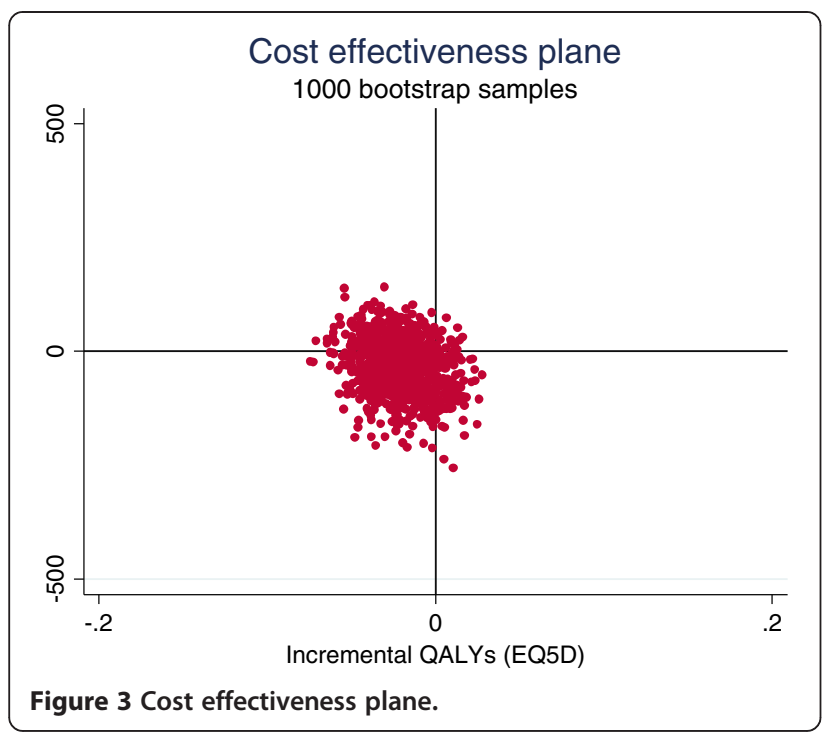

interaction, physiotherapist's confidence in the treatment, or the patients' confidence in the physiotherapist thus reducing the therapeutic effectiveness of the encounter. There is, for example, evidence that acupuncture is more effective when delivered by an enthusiastic practitioner rather than a neutral or negative practitioner [53]. In this trial we did not include a process evaluation that might have shed light on these issues. Future trials of similar tools should include such an evaluation.

\section{Conclusion}

Although our findings are specific to our approach to improving choice of back pain treatments, our findings may be of considerable importance more generally. The way in which risk information is presented can influence decisions made [54]. Our results add to the evidence that it cannot be assumed that the provision of additional information and support for patients to achieve informed decisions is risk free. Before decision aids are implemented they should be formally evaluated to ensure safety as well as efficacy and cost-effectiveness.

\section{Additional files}

Additional file 1: Intervention Booklet.

Additional file 2: Table S1. Unit costs for NHS services, tests and drugs. Additional file 3: Table S2. Mean NHS costs (£): $0-4$ months.

Additional file 4: Figure S1. Cost effectiveness acceptability curve.

Additional file 5: Table S3. Analysis of primary and secondary outcomes excluding participants seen by physiotherapists who joined post randomisation. Proportions and relative risk (usual care against decision support package) for the primary outcome, satisfaction with treatments. Mean change from baseline and difference between treatments for secondary outcomes. All estimates with $95 \%$ confidence interval.

\section{Abbreviations}

QALs: Quality adjusted life years; NHS: National Health Service; NICE: National Institute for Health and Care Excellence; RCT: Randomised controlled trial; SF12: Short form 12; EQ-5D: EuroQol-5 dimensions; RMDQ: Roland Morris disability questionnaire; ICC: Intra-cluster correlation coefficient; MICE: Multivariate imputation using chained equations; IPDAS: International patient decision aid standards collaboration.

\section{Competing interests}

All authors declare: financial support for the submitted work from the NIHR; MU received grants from NIHR Research for Patient Benefit Programme and NIHR Senior Investigator award during the conduct of the study. Outside the submitted work MU also received support from NICE, BMJ learning, and Osteoarthritis Research Society International; he is director and shareholder of and Clinvivo Ltd.

\section{Authors' contributions}

SP together with MU was primarily responsible for study design, day to day management of the study, data collection, analysis, and interpretation. SP was responsible for first draft and finalisation of the paper. AN together with $\mathrm{SP}$, assisted with the day to day management of the trial, assisted with data collection and reviewed the manuscript. SWH together with TF wrote the statistical analysis plan, conducted the analysis, interpreted the data and was responsible for writing the results section of the paper. YY with $J$ contributed to analysis and interpretation of the health economics data, and was responsible for writing the health economics section of the paper. SB and $\mathrm{CT}$ assisted with the study design, interpretation of results and reviewed draft manuscripts. TF was responsible for statistical design, contributed to statistical analyses and interpretation of results and reviewed the manuscript. FG contributed to the design of the study, interpretation of the data and helped critique the output for important intellectual content. JL was responsible for the health economic design, contributed to the health economic analysis and interpretation of the results and reviewed the manuscript. HS designed and delivered the physiotherapy training and reviewed the manuscript. JT contributed to the design of the study and in particular provided expertise and input into the design of the decision aid. JT has been involved in commenting on draft versions of the manuscript. MU together with SP was responsible for the study design and was the overall chief investigator responsible for the oversight of the study. MU contribution to analysis and interpretation of the data and helped draft this paper and critiqued the output for important intellectual content. All authors read and approved the final manuscript.

\section{Acknowledgements}

We would like to thank Mr Mark Woolvine for assisting with the recruitment of participants from the physiotherapy department and for the collection of resource use data from medical notes.

This paper presents independent research funded by the National Institute for Health Research (NIHR). The views expressed are those of the author(s) and not necessarily those of the NHS, the NIHR or the Department of Health. This project benefitted from facilities funded through Birmingham Science City Translational Medicine Clinical Research and Infrastructure Trials Platform, with support from Advantage West Midlands (AWM) and the Wolfson Foundation.

\section{Author details}

'Division of Health Sciences, Warwick Medical School, University of Warwick, CV4 7AL Coventry, UK. ${ }^{2}$ Department of Primary Care Health Sciences, Radcliffe Observatory Quarter, Oxford University, OX2 6GG Oxford, UK. ${ }^{3}$ Universities/User Teaching and Research Action Partnership (UNTRAP), University of Warwick, CV4 7AL Coventry, UK. ${ }^{4}$ Department of Medical Statistics, University Medical Centre Göttingen, Humboldtallee 32, D-37073 Göttingen, Germany. ${ }^{5}$ Health Economics Research Group, Brunel University, UB8 3PH Uxbridge, UK. ${ }^{6}$ Health Professions Education Consultant, Sydney, Australia. 


\section{References}

1. DH/NHS: Creating a Patient-led NHS: Delivering the NHS Improvement Plan; 2005.

2. Shared Decision Making. [http://www.rightcare.nhs.uk/index.php/shareddecision-making/about-the-sdm-programme/]

3. Siminoff $L A$, Gordon NH, Silverman P, Budd T, Ravdin PM: A decision aid to assist in adjuvant therapy choices for breast cancer. Psychooncology 2006, 15(11):1001-1013.

4. Ozanne EM, Annis C, Adduci K, Showstack J, Esserman L: Pilot trial of a computerized decision aid for breast cancer prevention. Breast J 2007 13(2):147-154

5. Tinsel I, Buchholz A, Vach W, Siegel A, Durk T, Buchholz A, Niebling W Fischer KG: Shared decision-making in antihypertensive therapy: a cluster randomised controlled trial. BMC Fam Pract 2013, 14:135.

6. Schapira MM, Gilligan MA, McAuliffe T, Garmon G, Carnes M, Nattinger AB: Decision-making at menopause: a randomized controlled trial of a computer-based hormone therapy decision-aid. Patient Educ Couns 2007, 67(1-2):100-107

7. Montgomery AA, Fahey T, Peters TJ: A factorial randomised controlled trial of decision analysis and an information video plus leaflet for newly diagnosed hypertensive patients. Br J Gen Pract 2003, 53(491):446-453.

8. O'Connor AM: Using decision aids to help patients navigate the "grey zone" of medical decision-making. CMAJ 2007, 176(11):1597-1598.

9. O'Connor AM, Rostom A, Fiset V, Tetroe J, Entwistle V, Llewellyn-Thomas H, Holmes-Rovner M, Barry M, Jones J: Decision aids for patients facing health treatment or screening decisions: systematic review. BMJ 1999 319(7212):731-734

10. Whelan T, Levine M, Willan A, Gafni A, Sanders K, Mirsky D, Chambers S, O'Brien MA, Reid S, Dubois S: Effect of a decision aid on knowledge and treatment decision making for breast cancer surgery: a randomized trial. JAMA 2004, 292(4):435-441.

11. Stacey D, Bennett $C L$, Barry MJ, Col NF, Eden KB, Holmes-Rovner M, Llewellyn-Thomas H, Lyddiatt A, Legare F, Thomson R: Decision aids for people facing health treatment or screening decisions. Cochrane Database Syst Rev 2011, 10:CD001431

12. Silva DD: Helping People Share Decision Making: A Review of Evidence Considering Whether Shared Decision Making is Worthwhile. London: The Health Foundation; 2012

13. Walsh T, Barr PJ, Thompson R, Ozanne E, O'Neill C, Elwyn G: Undetermined impact of patient decision support interventions on healthcare costs and savings: systematic review. BMJ 2014, 348:g188.

14. Andersson GB: Epidemiological features of chronic low-back pain. Lancet 1999, 354(9178):581-585.

15. Troup JDG: Back Pain and Epidemiology Review: The Epidemiology and Cost of Back Pain: Clinical Standards Advisory Group. In Her Majesty's Stationery Office London. ; 1994.

16. Maniadakis N, Gray A: The economic burden of back pain in the UK. Pain 2000, 84(1):95-103.

17. Waddell G, Burton AK: Occupational health guidelines for the management of low back pain at work: evidence review. Occup Med 2001, 51(2):124-135.

18. Vos T, Flaxman AD, Naghavi M, Lozano R, Michaud C, Ezzati M, Shibuya K, Salomon JA, Abdalla S, Aboyans V, Abraham J, Ackerman I, Aggarwal R, Ahn SY, Ali MK, Alvarado M, Anderson HR, Anderson LM, Andrews KG, Atkinson C, Baddour LM, Bahalim AN, Barker-Collo S, Barrero LH, Bartels DH, Basanez MG, Baxter A, Bell ML, Benjamin EJ, Bennett D, et al: Years lived with disability (YLDs) for 1160 sequelae of 289 diseases and injuries 1990-2010: a systematic analysis for the Global Burden of Disease Study 2010. Lancet 2012, 380(9859):2163-2196.

19. Savigny PKS, Watson $P$, Underwood M, Ritchie G, Cotterell M, Hill D, Browne N, Buchanan E, Coffey P, Dixon P, Drummond C, Flanagan M, Greenough C, Griffiths M, Halliday-Bell J, Hettinga D, Vogel S, Walsh D: Low Back Pain: Early Management of Persistent Non-Specific Low Back Pain. London: National Collaborating Centre for Primary Care and Royal College of General Practitioners; 2009

20. Campbell C, Guy A: 'Why can't they do anything for a simple back problem?' A qualitative examination of expectations for low back pain treatment and outcome. J Health Psychol 2007, 12(4):641-652.

21. Crowe M, Whitehead L, Gagan MJ, Baxter GD, Pankhurst A, Valledor V: Listening to the body and talking to myself - the impact of chronic lower back pain: a qualitative study. Int J Nurs Stud 2010, 47(5):586-592.
22. Crowe M, Whitehead L, Jo Gagan M, Baxter D, Panckhurst A: Self-management and chronic low back pain: a qualitative study. J Adv Nurs 2010, 66(7):1478-1486.

23. Farin E, Gramm L, Schmidt E: Predictors of communication preferences in patients with chronic low back pain. Patient Preference Adherence 2013. 7:1117-1127.

24. Laerum E, Indahl A, Skouen JS: What is "the good back-consultation"? A combined qualitative and quantitative study of chronic low back pain patients' interaction with and perceptions of consultations with specialists. J Rehabil Med 2006, 38(4):255-262.

25. May S: Patients' attitudes and beliefs about back pain and its management after physiotherapy for low back pain. Physiother Res Int 2007, 12(3):126-135.

26. Nielsen M, Jull G, Hodges PW: Information needs of people with low back pain for an online resource: a qualitative study of consumer views. Disabil Rehabil 2014, 36(13):1085-1091.

27. Slade SC, Molloy E, Keating JL: 'Listen to me, tell me': a qualitative study of partnership in care for people with non-specific chronic low back pain. Clin Rehabil 2009, 23(3):270-280

28. Sokunbi O, Cross V, Watt P, Moore A: Experiences of individuals with chronic low back pain during and after their participation in a spinal stabilisation exercise programme - a pilot qualitative study. Man Ther 2010, 15(2):179-184.

29. Charles C, Gafni A, Whelan T: Shared decision-making in the medical encounter: what does it mean? (or it takes at least two to tango). Soc Sci Med 1997, 44(5):681-692.

30. Stevenson FA, Barry CA, Britten N, Barber N, Bradley CP: Doctor-patient communication about drugs: the evidence for shared decision making. Soc Sci Med 2000, 50(6):829-840.

31. Patel S, Brown S, Friede T, Griffiths F, Lord J, Ngunjiri A, Thistlethwaite J, Tysall C, Woolvine M, Underwood M: Study protocol: improving patient choice in treating low back pain (IMPACT-LBP): a randomised controlled trial of a decision support package for use in physical therapy. BMC Musculoskelet Disord 2011, 12:52.

32. Patel S, Ngunjiri A, Sandhu H, Griffiths F, Thistlethwaite J, Brown S, Friede T, Lord J, Tysall C, Woolvine M, Underwood M: The design and development of a decision support package for low back pain. Arthritis Care Res (Hoboken) 2014, 66(6):925-33(6):925-933.

33. Holmes-Rovner M, Kroll J, Schmitt N, Rovner DR, Breer ML, Rothert ML, Padonu G, Talarczyk G: Patient satisfaction with health care decisions: the satisfaction with decision scale. Med Decis Mak 1996, 16(1):58-64.

34. Roland M, Morris R: A study of the natural history of back pain: Part I: development of a reliable and sensitive measure of disability in low-back pain. Spine 1983, 8(2):141-144

35. Von Korff M, Ormel J, Keefe FJ, Dworkin SF: Grading the severity of chronic pain. Pain 1992, 50(2):133-149.

36. Garratt AM, Ruta DA, Abdalla MI, Buckingham JK, Russell IT: The SF36 health survey questionnaire: an outcome measure suitable for routine use within the NHS? BMJ 1993, 306(6890):1440-1444.

37. EuroQol Group: EuroQol-a new facility for the measurement of health-related quality of life. Health Policy 1990, 16(3):199-208.

38. Zigmond AS, Snaith RP: The hospital anxiety and depression scale. Acta Psychiatr Scand 1983, 67(6):361-370.

39. Nicholas MK: The pain self-efficacy questionnaire: taking pain into account. Eur J Pain 2007, 11(2):153-163.

40. Waddell G, Newton M, Henderson I, Somerville D, Main CJ: A Fear-Avoidance Beliefs Questionnaire (FABQ) and the role of fear-avoidance beliefs in chronic low back pain and disability. Pain 1993, 52(2):157-168.

41. Friede T, Kieser M: Sample size recalculation in internal pilot study designs: a review. Biom J 2006, 48(4):537-555.

42. Chakraborty H, Moore J, Carlo WA, Hartwell TD, Wright LL: A simulation based technique to estimate intracluster correlation for a binary variable. Contemp Clin Trials 2009, 30(1):71-80.

43. NloHaCE: NICE Guide to the Methods of Technology Appraisal. London: NICE; 2008.

44. Ramsey S, Willke R, Briggs A, Brown R, Buxton M, Chawla A, Cook J, Glick H, Liljas B, Petitti D, Reed S: Good research practices for cost-effectiveness analysis alongside clinical trials: the ISPOR RCT-CEA Task Force report. Value Health 2005, 8(5):521-533.

45. Willan AR, Briggs AH, Hoch JS: Regression methods for covariate adjustment and subgroup analysis for non-censored cost-effectiveness data. Health Econ 2004, 13(5):461-475. 
46. Artus M, van der Windt DA, Jordan KP, Hay EM: Low back pain symptoms show a similar pattern of improvement following a wide range of primary care treatments: a systematic review of randomized clinical trials. Rheumatology 2010, 49(12):2346-2356.

47. Froud R: Improving Interpretation of Patient-Reported Outcomes in Low Back Pain Trials, PhD thesis. London: Queen Mary University; 2010.

48. UK BEAM Trial Team: United Kingdom back pain exercise and manipulation (UK BEAM) randomised trial: effectiveness of physical treatments for back pain in primary care. BMJ 2004, 329(7479):1377.

49. Lamb SE, Hansen Z, Lall R, Castelnuovo E, Withers EJ, Nichols V, Potter R, Underwood MR: Group cognitive behavioural treatment for low-back pain in primary care: a randomised controlled trial and costeffectiveness analysis. Lancet 2010, 375(9718):916-923.

50. Elwyn G, O'Connor A, Stacey D, Volk R, Edwards A, Coulter A, Thomson R, Barratt A, Barry M, Bernstein S, Butow P, Clarke A, Entwistle V, FeldmanStewart D, Holmes-Rovner M, Llewellyn-Thomas H, Moumjid N, Mulley A, Ruland C, Sepucha K, Sykes A, Whelan T: Developing a quality criteria framework for patient decision aids: online international Delphi consensus process. BMJ 2006, 333(7565):417.

51. Coulter A, Kryworuchko JMP, Ng CJ, Stilwell D, van der Weijden T: Using a Systematic Development Process. In Update of the International Patient Decision Aids Standards (IPDAS) Collaboration's Background Document. Edited by Volk R, Llewellyn-Thomas H. ; 2012.

52. Kurtz S, Silverman J, Benson J, Draper J: Marrying content and process in clinical method teaching: enhancing the Calgary-Cambridge guides. Acad Med 2003, 78(8):802-809.

53. Suarez-Almazor ME, Looney C, Liu Y, Cox V, Pietz K, Marcus DM, Street RL: A randomized controlled trial of acupuncture for osteoarthritis of the knee: effects of patient-provider communication. Arthritis Care Res (Hoboken) 2010, 62(9):1229-1236.

54. Edwards A, Elwyn G, Covey J, Matthews E, Pill R: Presenting risk information-a review of the effects of "framing" and other manipulations on patient outcomes. J Health Commun 2001, 6(1):61-82.

doi:10.1186/1471-2474-15-282

Cite this article as: Patel et al:: Primum non nocere: shared informed decision making in low back pain - a pilot cluster randomised trial. BMC Musculoskeletal Disorders 2014 15:282.

\section{Submit your next manuscript to BioMed Central and take full advantage of:}

- Convenient online submission

- Thorough peer review

- No space constraints or color figure charges

- Immediate publication on acceptance

- Inclusion in PubMed, CAS, Scopus and Google Scholar

- Research which is freely available for redistribution 